\title{
Oil Flax Straw Processing and Utilization
}

\author{
Sergey N. Nikolsky, Dmitry V. Zlenko*, \\ Andrey K. Gatin, Mariya G. Mikhaleva, \\ Galina G. Politenkova, Alexey A. Lin, \\ Igor K. Ermolin, and Sergey V. Stovbun
}

7 Received: date / Accepted: date

\begin{abstract}
The flax (Linum usitatissimum) is widely used as a source of linen oil and fiber. As a rule, the flax varieties serve to produce either seeds (oil), or stem fibers, as the "fiber" varieties bring the low amount of seeds, while the "oil" varieties have poor fibers that cannot be used in textile. The straw of the oil flax has not been applied in industry and has to be burned or degrade naturally in the field. However, it contains a low degree of polymerization cellulose, which can be used at least for varnish production. The main challenge in the industrial application of the oil flax cellulose is the necessity of separating the cellulose fibers and shive enriched 6 in lignin. On the other hand, the low cost of the final products restricts the set of available tools. Here we describe a machine designed for oil flax straw stripping and several ways of further conversion of the obtained tow into microcrystalline or fluff-like cellulose. The supposed processes run at the temperatures below the water boiling point and at the atmospheric pressure and could be held in the plastic reactors.
\end{abstract}

Keywords Oil flax straw · fluff cellulose $\cdot$ Linum usitatissimum

\section{Introduction}

Flax (Linum usitatissimum) is an annual herbaceous plant cultivated for fiber (socalled "fiber" flax) or oil (so-called "seed" or "oil" flax) production. The linen oil

The work was completed as a part of the state assignment (theme number AAAA-A20120013190076-0)

S. Nikolsky, D. Zlenko, A. Gatin, M. Mikhaleva, G. Politenkova, A. Lin, and S. Stovbun N.N. Semenov Federal Research Center for Chemical Physics, Russian Academy of Sciences, Moscow, Russia

D. Zlenko

M.V. Lomonosov Moscow State University, Moscow, Russia

A.N. Severtsov Institute of Ecology and Evolution, Moscow, Russia

*dvzlenko@gmail.com

I. Ermolin

LLC "RIM", Torzhok, Russia 
is produced from the seeds of the oil flax, while the stalks remain in the field to degrade naturally or to be burned similar to the wheat's, oats', rice's, and soybeans' straw (Anthony, 2005; Buranov and Mazza, 2010; Gismatulina et al., 2016) The flax straw natural degradation time is much longer than that of other common agricultural crops.(Anthony, 2002) Therefore, oil flax straw utilization became one of the key problems for reasonable modern agriculture.

The oil flax fiber is usually shorter than that of fiber flax, making it inappropriate for the textile industry. However, it could be suitable for various non-textile applications, such as the reinforcing material in composites (Foulk et al., 2011; Zykova et al., 2011; Azhar et al., 2020), or production of the cellulose nitrates (Gismatulina et al., 2016; Sakovich et al., 2018) and linen paper (Schafer and Curran, 1938; Dillman, 1943; Wells, 1949). The oil flax fiber is tough to separate from the wooden and lignin-rich fraction known as "shive" (Anthony, 2005; Tavisto et al., 2003; Chursina et al., 2019). Shive composes approximately $50 \%$ in weight of the dry flax stems, making it one of the major by-product of the flax industry (Nuez et al., 2020; Barneto et al., 2011; Lazko et al., 2011). The shive itself also has many potential uses, such as wax (Tulloch and Hoffman, 1977; Athukorala et al., 2009) and lignin (Buranov and Mazza, 2008; Buranov et al., 2010) sources, the reinforcing additive (Lazko et al., 2011; Nuez et al., 2020) or fuel (Buranov and Mazza, 2008). However, flax shive cannot be used for animal feeding, first of all, due to the high lignin content in it (Buranov et al., 2010).

Besides the mechanical properties, the flax fiber and shive have a considerably different chemical composition that forces their separation for further utilization (Barneto et al., 2011). The long-fiber fraction of the flax pulp is enriched with glucans and xylans, while the short-fiber fraction is enriched with lignin (Barneto et al., 2011). Another complication is that the oil flax straw seems to be enriched by lignin compared to the fiber and intermediate flax, and these differences are mainly caused by the shive chemical composition (Baley, 2002; Determination of Cellulose and in Flax Fiber, 2009; Sakovich et al., 2018; Shaimerdenov et al., 2020). Therefore, the problem of effective separation of fiber and shive takes on a particular significance.

The latter problem was in the focus of several works dedicated to constructing the machines for oil flax fiber and shive separation (Anthony, 2002; Chursina et al., 2019). The machines proposed for this purpose were composed of several spiked cylinders serving for scrubbing the chopped flax straw followed by the cleaning saw (or several such saws) equipped with the cleaning brush (Anthony, $2002,2005)$. Such type of the machines allowed obtaining the final product (yield of 12-15\%) containing about 15-20\% of shive (Anthony, 2005). The spiked cylinders can be replaced by the stripping drums equipped with rigid beating planks and knives and separated by the tow-shaking conveyors (Chursina et al., 2019). The shive content was 20-25\%, which could be improved up to $0.05 \%$ by processing on combers. Unfortunately, the low quality of the final tow, which is not suitable for the textile industry, limits the overall cost of the shive removing process and makes, for example, the combers usage commercially unprofitable, despite the excellent purity of the fiber obtained. Therefore, cutting the cost of the oil flax fiber separation seems to be of crucial importance.

The modern literature on the oil flax cellulose utilization passing over the opportunity of flax papermaking, while such a possibility was discussed in the middle of 20-th century (Dillman, 1943). The main problem of papermaking from 
oil flax is the same as in the textile industry, i.e., too short fibers. However, using the calcium hydroxide (milk of lime process) for raw delignification instead of more common today kraft and sulfite processes allows producing the fiber of sufficient for papermaking length (Schafer and Curran, 1938). We feel that this possibility undeservedly put behind. Another method of high-quality oil flax fiber production was shive precipitation by centrifugation of a diluted (solvent-to-pulp ratio 100) pulp suspension of the pulp retted in the caustic soda solution within 2472 hours (Wells, 1949). Despite the excellent purity of the final fiber, the described approach seems to be too expansive for commercial use.

In this work, we present the very simple approach to the separation of oil flax straw fiber from the shive, based on usage of the soft-bristles stripping drums able of processing of the dry straw directly in the field. Our approach does not require the preliminary retting and cutting stages, the stems could be processed as they are, which significantly decreases the time of processing and cost. Besides that, we have found several properties of the short-fiber oil flax cellulose that provides for its effective utilization.
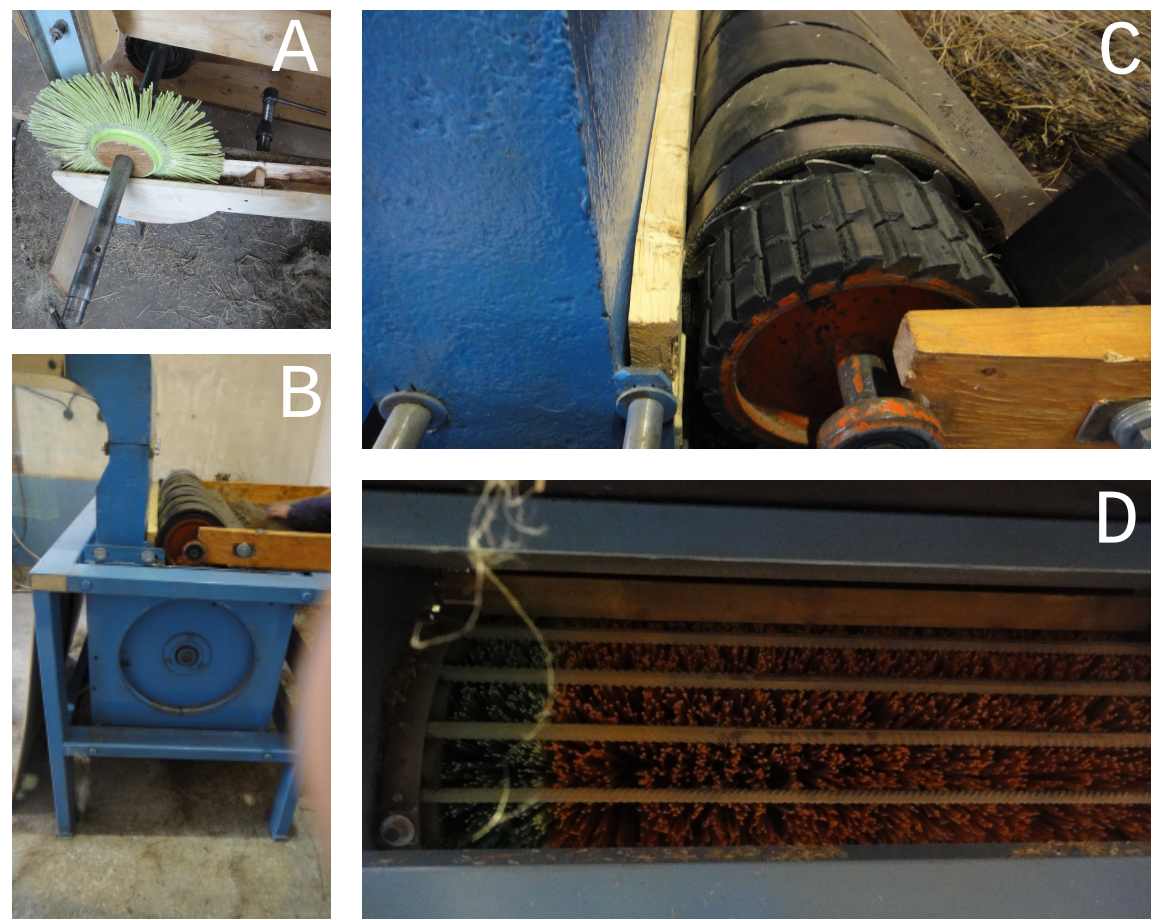

Fig. 1 The oil flax straw stripping machine ( $500 \mathrm{~kg}$ of straw per hour, $\mathrm{W}=6.5 \mathrm{~kW})$. A. A stripping brush on a shaft (diameter $550 \mathrm{~mm}$ ); B. The flax straw stripping machine; C. The feeding part of the machine; D. A stripping roll composed of several soft-bristle brushes (as in part A) on a shaft inside the straw stripping machine. 
2 Materials and Methods

\subsection{Analytical approaches}

The fraction of alpha-cellulose was determined as the proportion of cellulose insoluble in $17.5 \% \mathrm{NaOH}$ (Richter, 1929). The molecular weight and the degree of polymerization (DP) of the original cellulose were determined by the viscosity of a copper-ammonium solution of cellulose (Whorlow, 1980). The moisture content in the specimens was determined by the change in the sample's mass (sample weight $10 \mathrm{~g}$, the scale tolerance $1 \mathrm{mg}$ ) after drying at $105 \pm 2{ }^{\circ} \mathrm{C}$ until the constant weight, according to GOST 16932-93 (ISO/DIS 638-1/638-2). The degree of crystallinity was determined using the "peak height" method (Terinte et al., 2011). $\mathrm{X}$-ray diffraction analysis of the samples was performed using a DRON-3 X-ray diffractometer (burevestnik, Saint-Petersburg, Russia) with a copper anticathode and a nickel filter, operating at $30 \mathrm{kV}$ and $20 \mathrm{~mA}$. A comparative analysis of the micro-crystalline cellulose (MCC) particles' size was performed using a Fritsch Analysette 22 MicroTec plus instrument $(0.08-2000 \mu \mathrm{m})$.

The Solver HV microscope (LLC NT-MDT, Russia) was used for the atomic force microscopy (semi-contact mode, room temperature, and atmospheric pressure). Solver HV was equipped with the standard cantilevers (LLC NT-MDT, Russia) with the natural frequencies of $110-180 \mathrm{kHz}$ and a tip radius of $10 \mathrm{~nm}$. The UV-spectra of the samples were recorded using the SF-104 spectrofotometer (NPO Akvilon, Saint Petersburg, Russia).

Water absorbency was assessed by the mass of the water that the sample of MCC can retain. A dried sample of MCC (15 g, humidity 5-6\%) was placed in the metal cylinder $(70 \mathrm{~mm}$ in diameter) with a drilled bottom. The sample was beaten down to the thickness of $50 \mathrm{~mm}$. The cylinder with the sample was weighted $( \pm 10 \mathrm{mg})$ and submersed into the distilled water for $30 \mathrm{sec}$ to provide for the complete wetting of the cellulose. After that, the cylinder was taken away from the water, bled down for $30 \mathrm{sec}$, and weighted again. The ratio of the retained water mass and the weight of the initial cellulose (water retention value, WRV) sample was used as a measure of water absorbency (GOST 595-79, Lund et al. (2012))

\subsection{Flax straw processing}

The oil flax straw (breed LM-98, Fig. 3A) was obtained from the All-Russian Research Institute of Flax (Torzhok, Russia). Seed yield was about 6.5 centner per hectare. Oil content was $\sim 43 \%$ (linoleic acid $\sim 69 \%$ and linolenoic acid $\sim 4 \%$ ). By now, the straw does not utilized and degrades naturally in the field.

The mechanical treatment of the oil flax straw was a one-stage process in a novel machine (Fig. 1). Neither preliminary cutting nor retting was required; the straw was processed immediately after the seeds collecting. The novel machine designed for the straw stripping was straightforward and composed of a set of circular brushes (Fig. 1A) with a rather soft polypropylene bristle equipped with a feed channel and tanks for fiber and shive (Fig. 3B and 3C, respectively). The essential feature of the proposed machine was a soft polypropylene bristle (1.5$3.0 \mathrm{~mm}$ in thickness and $\sim 220 \mathrm{~mm}$ in length) allowed obtaining the tow with a 
shive content of about $15 \%$ (Fig. 3B), which is a rather good result (Anthony, $2005)$. Reducing the processing stages allowed decreasing the power consumption down to $6.5 \mathrm{~kW}$ per $500 \mathrm{~kg}$ of the initial straw per hour. The obtained tow was rather long-fiber and had a tendency to clump, so after the stripping, the tow was cut into the $5-10 \mathrm{~cm}$ pieces.

The mechanical processing was followed by a two stage chemical treatment of the obtained oil flax tow. The first stage was a delignification in $5 \%$ solution of $\mathrm{NaOH}$ or $\mathrm{NaHCO}_{3}$ at $95^{\circ} \mathrm{C}$ for 120 minutes (solvent-to-pulp ratio 50). Here and hereafter, the former cellulose will be refereed to as "alkali cellulose", while the latter - as "bicarbonate cellulose" The process was held in a plastic tank instead of the metal boilers necessary for the kraft and sulfite processes. The resulting pulp was rinsed with fresh cold water (water consumption $15 \mathrm{~kg} / \mathrm{kg}$ ) until the neutral $\mathrm{pH}$. At the next step, the pulp was bleached using $1 \% \mathrm{H}_{2} \mathrm{O}_{2}$ solution at $95{ }^{\circ} \mathrm{C}$ for 90 minutes ( $\mathrm{pH} 5.5-5.7$, solvent-to-pulp ratio 50). The $\mathrm{NaHCO}_{3}$-delignified pulp required the bleaching procedure to be repeated three times to achieve the brightness comparable to the $\mathrm{NaOH}$-delignified one. The bleached pulp was rinsed with fresh cold water (water consumption $15 \mathrm{~kg} / \mathrm{kg}$ ) and dried (Fig. 2).

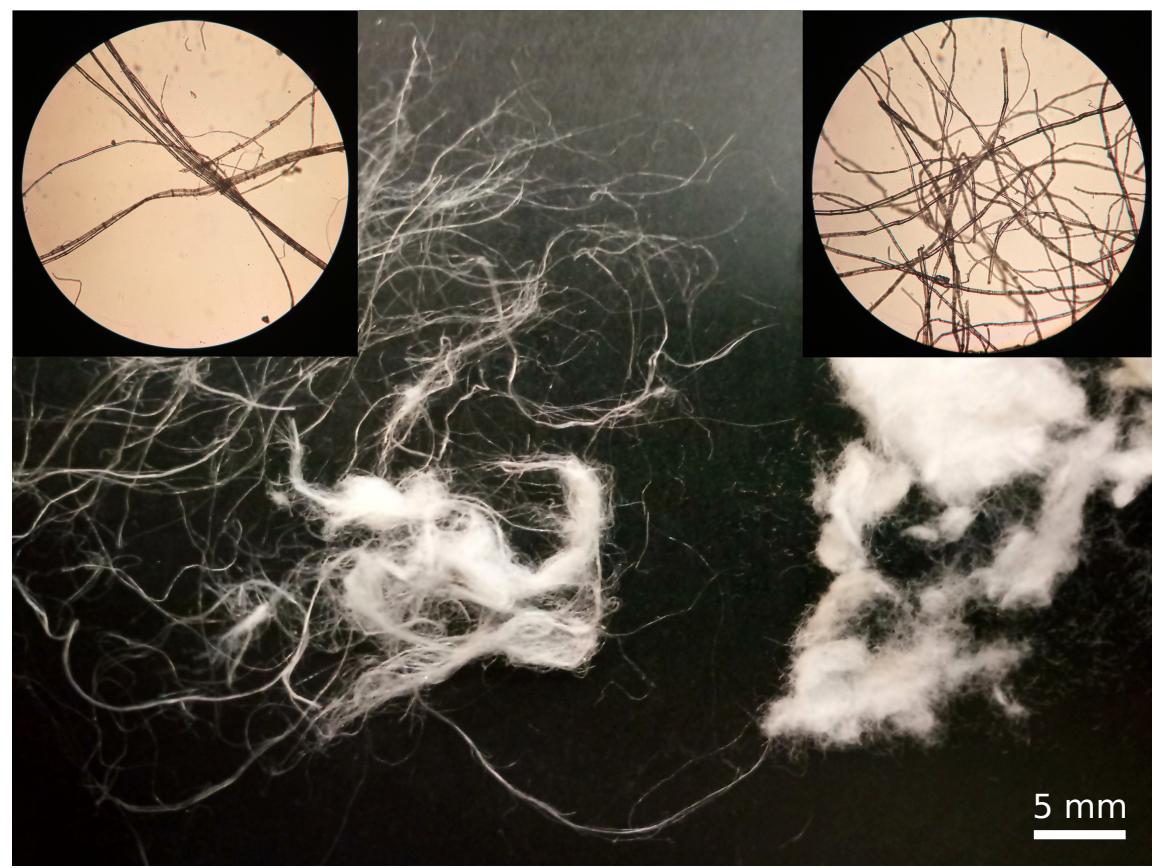

Fig. 2 The bleached oil flax cellulose delignified in $\mathrm{Na}_{2} \mathrm{CO}_{3}$ (on the left) and $\mathrm{NaOH}$ (on the right). The insets represent the optical microscope images $(x 10)$ of the corresponding cellulose materials. 
2.3 Paper production

The bicarbonate oil flax cellulose was not used for the laboratory paper samples production due to significant share of very long (several centimeters) fibers. The bleached alkali flax cellulose (sample weight $16 \pm 0.5 \mathrm{~g}$ ) was retted in distilled water $(500 \mathrm{ml}$ room temperature) for 24 hours. The retted pulp was diluted to $1100 \pm 20 \mathrm{ml}$ with the distilled water (cellulose concentration $1.5 \%$ ) and disintegrated with an impeller (3000 rmp) for $10 \mathrm{~min}$ to homogenize the raw additionally. The resulting pulp was concentrated using a Büchner funnel and diluted with a distilled water to $265 \pm 5 \mathrm{ml}$ (cellulose concentration $6 \%$ ). The diluted pulp was ground using a JOKRO mill (PTA, Saint-Petersburg, Russia) with a shaft rotation speed of $150 \mathrm{rpm}$ (10 min, room temperature). The grinding was followed with an additional 3 min desintegration stage.

The obtained cellulose pulp was diluted to the cellulose concentration of $0.24 \%$ and one liter of the diluted suspension was used for the paper casting $(24 \mathrm{~g}$ per $320 \mathrm{~cm}^{2}$ of the paper-casting camera results in the paper sample having the density of approximately $\left.75 \mathrm{~g} / \mathrm{m}^{2}\right)$. The suspension was thrown down on the porous membrane under vacuum (suction pressure did not exceed $27 \mathrm{kPa}$ ). After the sedimentation, the cellulose mass was covered with glazed cardboard and pressed with a squeezing roll. The obtained paper castings on the cardboard sheet were covered with a sheet of paper and dried in the vacuum camera (96 kPa, 7-10 min). After the vacuum drying the samples were equilibrated at the relative humidity of $50 \pm 2 \%$ (room temperature, $150 \mathrm{~min}$ ).

\subsection{Microcrystalline cellulose production}

The microcrystalline cellulose was prepared from the alkali-delignified flax cellulose. To produce the microcrystalline cellulose, the bleached alkali flax cellulose was hydrolyzed in the aqueous solution of sulfuric acid (10\%) for 2 hours at 95$97^{\circ} \mathrm{C}$ (solvent-to-pulp ratio 30 ). After the regeneration (we have filtered the solution on a glass filter and added the acid to the density of $1.066 \mathrm{~g} / \mathrm{cm}^{3}$ ), the sulfuric acid solution could be reused for the hydrolysis of the next portion of the tow. The reaction was stopped by rinsing with cold distilled water on a glass filter. Then, the pulp was squeezed out on a glass Nutsche filter (Rusredmet, Saint-Petersburg, Russia), rinsed with cold distilled water until neutral pH (water consumption $15 \mathrm{~kg} / \mathrm{kg}$ ) and dried in the air. The flax cellulose suspension (cellulose concentration 8-10\%) was ground using a ball mill (BMR/60, LLC Tekhno-center, Rybinsk, Russia). The result was a white, homogeneous, finely dispersed powder (Fig. 3E).

We have verified the flax MCC susceptibility to the grinding into the nanocellulose (NC). For this purpose, we used a ceramic pounder where the pulp was treated for one hour. Such an approach was used to demonstrate the easiness of the flax cellulose grinding process compared to other cellulose sources. The MCC suspension ( $\sim 750 \mathrm{mg}$ of cellulose) was dispersed in distilled water (solvent-topulp ratio 5) and then ground. The residual MCC was precipitated by centrifugation (10 min, $3500 \mathrm{rpm}$ ), and the resulted supernatant was analyzed. The NC concentration was accessed by the weight change after the water evaporation $( \pm 5 \mathrm{mg}$.) 


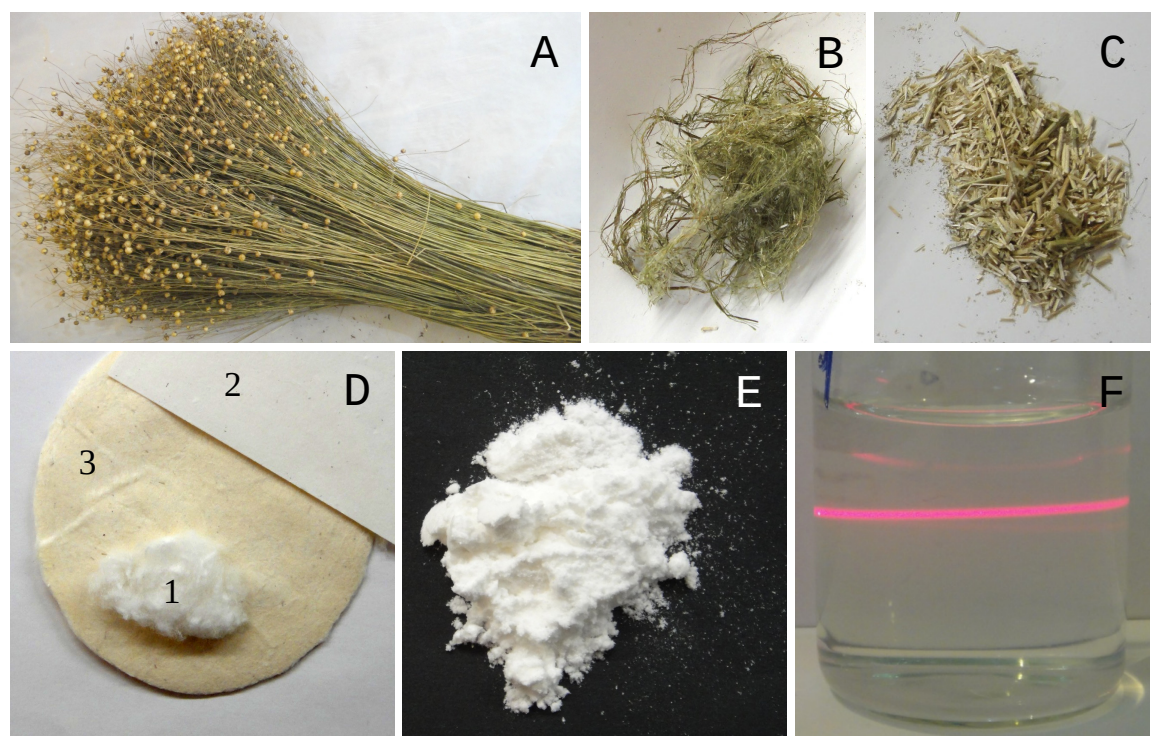

Fig. 3 The oil flax straw processing. A. The initial straw with the seeds; B. Flax tow after the mechanical treatment; C. The shive separated fron the fiber; D. Bleached flax cellulose (1) and paper samples made of bleached (2) and unbleached flax cellulose (3); E. Microcrystalline cellulose from flax; F. The light scattering in the "cellulose hydrogel" obtained by the grinding of the MCC in a roller-ball mill.

\section{Results and Discussion}

The suggested approach to the oil flax straw utilization is advantageous due to the simplicity of the stripping machine used for tow and shive separation (Fig. 1) and relatively low power consumption of about $6.5 \mathrm{~kW}$ per $500 \mathrm{~kg}$ of the straw per hour ( $\sim 150 \mathrm{~kg}$ of the final cellulose). In fact, our machine is composed of only several stripping brushes with the soft polypropylene bristle. The designed device allows preparing the ready for chemical treatment tow using costless raw and spending approximately the same energy as, for example, the wood-cutting machines used for chips production in the wood cellulose technological chain.

The oil flax straw delignification was held at the temperature below the water boiling point, allowing to hold it at the atmospheric pressure in the plastic reactor. Using the plastic tanks instead of the thick-wall metal ones provides for the dramatic simplification and cost reduction of the delignification process compared to the classic kraft and sulfite processes and traditional wood or cotton raw.

The properties of the alkali oil flax cellulose were as follows. The residual moisture content was not more than $8 \%$, and the residual lignin content was not more than $0.2 \%$ (according to the UV spectroscopy). The weight fraction of the $\alpha$ cellulose after the stripping was $87.9 \mathrm{pm} 1.2 \%$, while after the chemical treatment and bleaching it grew up to $92.0 \pm 0.9 \%$. The whiteness of the flax cellulose before bleaching was $61 \pm 1 \%$, while after the bleaching it grew up and composed at least $86 \%$. The yield of the tow after the shive removal was approximately $25 \%$, and the yield of the purified and bleached cellulose was about $65 \%$ of the tow weight $(\sim$ $16 \%$ of the flax straw initial weight). All of the obtained general characteristics 
of the final product were common for celluloses from other sources. The only and significant peculiarity of the obtained cellulose was rather low DP of $120-$ 130 (according to the copper-ammonium solution viscosity). The latter restricts the applications of the alkali oil flax cellulose.

The alkali and bicarbonate oil flax celluloses were significantly different. The alkali cellulose as composed of rather thin $(10-15 \mu \mathrm{m})$, fibers having single-cell thickness and a length of several millimeters (Fig. 2, on the right). On the contrary, the bicarbonate cellulose contained a significant $(\sim 60-60 \%)$ share of very long (up to $5-7$ centimeters), thick $(30-40 \mu \mathrm{m})$ and rather hard (1-2 g until break) fibers, composed of several (5-10) not macerated single-cell fibers (Fig. 2, on the left). Despite the resistance to the bleaching procedure, the residual lignin content in the final (bleached) bicarbonate cellulose was pretty low $(0.5 \%)$.

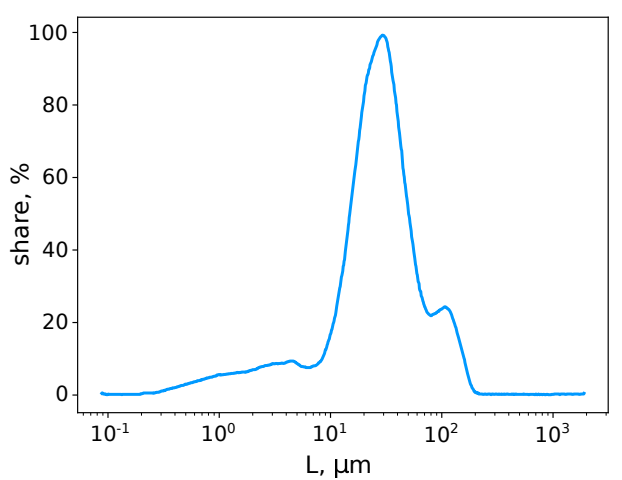

Fig. 4 The seed flax MCC (Fig. 3E) particles size disctribution.

The cellulose has a complex supramolecular structure composed of several included superhelical structural levels (elementary fibrils, microfibrils, and the cell walls as a whole), so any process in the cellulose pulp appears to be related to the pulp reorganization and at least partial untwisting of some of these superhelices (Nikolsky et al., 2019; Zlenko et al., 2019a). The oil flax cellulose has an extremely low DP of about 120-130; therefore, the cellulose chains have only about $60-65 \mathrm{~nm}$ in length ( $\sim 5 \AA$ per residue). The characteristic helical pitch of cellulose elementary fibril is $\sim 100 \mathrm{~nm}$ (Fernandes et al., 2011; Zhao et al., 2013), so the cellulose chains do not make even a single full turn around each other. According to the capstan equation (Nikolsky et al., 2019):

$$
F_{f r i c} \sim e^{2 \pi k n}
$$

The friction force $\left(F_{f} r i c\right)$ strongly depends on the number of the mutual turns of the fibers $(n)$ forming a helical bundle ( $k$ - is a friction coefficient). Following our hypothesis on the friction forces' role in controlling the rates of the processes in the cellulose pulp (Nikolsky et al., 2019; Zlenko et al., 2019a; Stovbun et al., 2020), the flax cellulose having very low DP should nitrate and delignify easily. The good amenability of the flax cellulose to nitration was reported earlier, and here we demonstrate the possibility of its purifying from the lignin in a relatively mild condition. 
Trying to suggest the technological application of the obtained celluloses, we have tested the paper-forming properties of the obtained alkali flax cellulose. Despite the suitable whiteness of $86 \%$ (Fig. 3D), the mechanical properties of the obtained paper were rather poor. The breaking length was only $2.4 \mathrm{~km}$ and breaking strength was $24.5 \mathrm{kN}$. The length of the cellulose fibers after the grinding using shear-stress mill (JOKRO) was in the range $0.2-10.0 \mathrm{~mm}(1.0 \mathrm{~mm}$ on average), while the thickness of the fibers was in the range $5-75 \mu \mathrm{m}$ (22 $\mu \mathrm{m}$ on average). Such a length is too short for paper production (Ververis et al., 2004) that could be a reason for the poor properties of the obtained paper.

The low paper-making properties of the alkali oil flax cellulose also reflect its unsuitability for the textile industry, as the too-short (several millimeters) fibers cannot be used for yarn spinning. On the other hand, the bicarbonate oil flax cellulose was composed of much longer and rather strong fibers that could be used for yarn. Moreover, the strong grades of paper used for banknotes production are usually made of long-fiber cotton cellulose (Lujan-Ornelas et al., 2018; Yousef et al., 2020). Therefore, the bicarbonate cellulose theoretically could be used for the same purposes, but in a pure, it has too long fibers for papermaking. Nevertheless, the addition of some amount of the longer bicarbonate fibers to the short-fiber alkali flax cellulose would reinforce too weak alkali paper and result in high-durability oil flax paper suitable even for money-printing.

On the other hand, the low DP of the obtained alkali oil flax cellulose is suitable for nitration and varnishes production (Liu, 2019), as the flax cellulose is known to nitrate normally (Gismatulina et al., 2016; Sakovich et al., 2018). Low DP and the corresponding relatively short fibers makes the alkali flax cellulose fragile. This peculiarity should ease up the fibers' disintegration in the fashion of the fluff cellulose pulps production. Indeed, the obtained cellulose showed significant water absorbency of 9 ( $135 \mathrm{~g}$ of water per $15 \mathrm{~g}$ of cellulose), which is, in general, familiar with fluff pulps rather than the raw celluloses (Lund et al., 2012). The fluffing of the oil flax cellulose without any additional treatment is provided by the same small friction force between the short chains and fibrils in the pulp, which makes the alkali oil flax paper and yarn not strong.

The fluff pulps are widely used as absorbents in baby diapers and feminine hygiene products, but its production technology requires significant energy expenditures on the burst heating of the wet raw by the rollers of the Fourdrinier machine (Hubbe et al., 2013). In the case of the obtained alkali oil flax cellulose, this stage is omitted that significantly decreases the amount of energy necessary to produce the final product. Therefore, using the cheap oil flax cellulose instead of rather expensive fluff pulps as the water-absorbent would significantly reduce the cost of many essential day-to-day goods.

The loose, fluff-like structure of the obtained alkali cellulose allowed supposing it to be a good raw for further milling to produce the microcrystalline (MCC) and nano-cellulose (NC). The MCC was obtained in relatively mild conditions (95$97^{\circ} \mathrm{C}$, atmospheric pressure) suitable also for the hardwood cellulose (Stovbun et al., 2020). The oil flax MCC was a bright white powder (Fig. 3E). Its properties were in agreement with generally accepted standards (Trache et al., 2016; El-Sakhawy and Hassan, 2007; Stovbun et al., 2020). The degree of crystallinity was $55 \pm 1 \%$, the bulk density of $0.20 \pm 0.03 \mathrm{~g} / \mathrm{ml}$, and the moisture content of $7.5 \pm 0.3 \%$. MCC particles were the cell fragments a bit shortened compared to the hardwood MCC (Stovbun et al., 2020) and equaled 20-50 $\mu$ in 
length. MCC particles' size distribution was bimodal, having maxima at $\sim 30$ and $\sim 105 \mu \mathrm{m}$ (Fig. 4). Considering the low cost of the initial raw, using the oil flax for MCC production could also be considered a potentially merchantable way of its straw utilization.
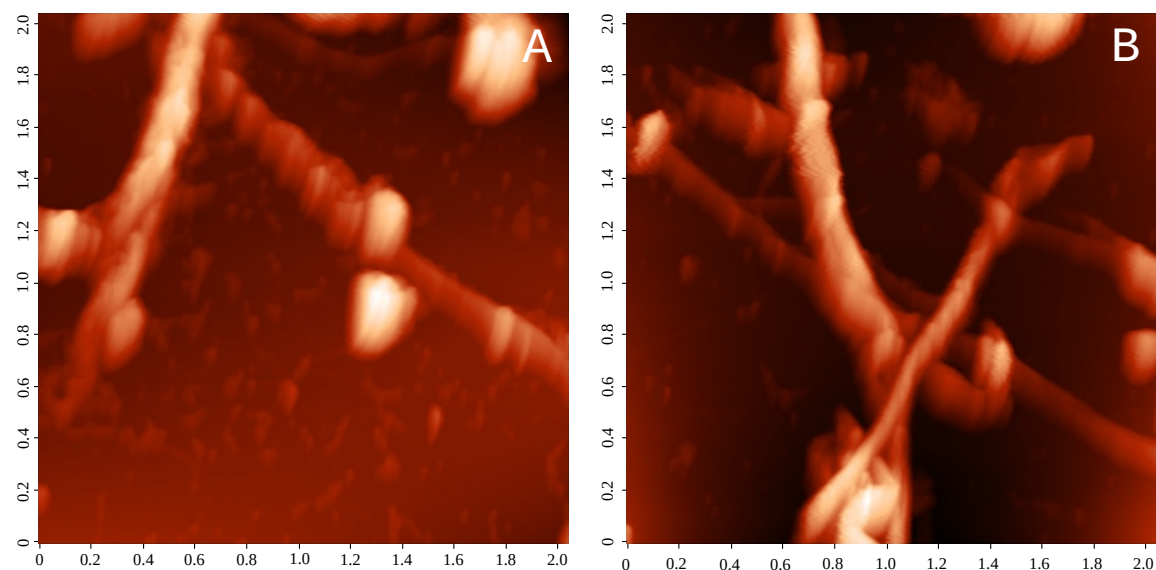

Fig. 5 The ASM images of the thin films(Stovbun et al., 2020) obtained by the evaporation of the diluted solutions of the hardwood (A) anf oil seed (B) nano-cellulose solutions.

The nano-cellulose could be prepared from the MCC by the chemical treatment followed by the intensive grinding or sonication (Zlenko et al., 2019a; Bondeson et al., 2006; Qing et al., 2013; Khalil et al., 2014). Earlier, we have shown that $\mathrm{NC}$ (in the form of cellulose nanofibrils, CNFs) forms in the MCC production process as a minor byproduct (Stovbun et al., 2020). Therefore, shortening of the MCC particles should promote the NC formation in mild treatment conditions (manual grinding using a ceramic mortar and pestle). The obtained NC suspension $(0.1 \%$ by weight) was a transparent liquid strongly scattering the laser radiation $(635 \mathrm{~nm}$, Fig. 3E). In total, one-hour manual treatment resulted in the conversion of $2.6 \%$ of the initial raw cellulose into NC. This allows making a lower-bound estimate on the size of the particles presented in the suspension as $\lambda / 20 \sim 30 \mathrm{~nm}$ (Zlenko et al., 2019b). The obtained NC was composed of the cellulose nano-fibrils (CNFs) that was confirmed by the AFM investigation (Fig. 5). The thin film obtained by the drying of the supernatant was composed of highly elongated helical elements of a considerable length, a diameter of about $50 \mathrm{~nm}$, and intertwined with each other (Stovbun et al., 2020; Qing et al., 2013; Khalil et al., 2014; Moon et al., 2011; Abitbol et al., 2016).

The supernatant obtained in the same procedure using the hardwood MCC (Stovbun et al., 2018) did not scatter the light beam, which clearly demonstrates the decreasing of the efforts necessary for oil flax NC production. The latter seems to be of particular importance as the commercially available machines designed for NC production of common raw (IKA, Germany) consume significant power that restricts the wide use of NC in industry. Therefore, the NC production also could be considered a potentially merchantable route of oil flax straw utilization. 


\section{Conclusion}

In conclusion, we would like to outline a significant theoretical observation crucial for any process in the cellulose pulp. Cellulose conversion into MCC is usually considered a kinetically-controlled process that could be accelerated by heating significantly above $100^{\circ} \mathrm{C}$ (Trache et al., 2016; Nsor-Atindana et al., 2017). However, in our experiments, the MCC was obtained at only $95^{\circ} \mathrm{C}$, including thoroughly conventional hardwood (Stovbun et al., 2020) and alkali oil flax cellulose. The $\mathrm{NC}$ was obtained from alkali oil flax cellulose by the simple manual pounding of the MCC instead of the treatment in the expensive high-impacting machines. The structure of the alkali oil flax cellulose was so loose that its properties appeared to be similar to the fluffed ones. The latter can be obtained by the burst heating of the wood or cotton cellulose. However, the short-length flax fibers did not require an additional steam impact, and the cellulose after delignification already had excellent water-absorbing properties.

We tend to explain the easiness of the alkali oil flax cellulose conversion to MCC and NC, as well as its fluff-like properties by lower friction forces that tie the supercoiled cellulose chains together apart from the conventional hydrogen and van-der-waals bonds. The friction force has a power-law dependency on the number of mutual twists of the chains (capstan equation), so even a minor decrease of the cellulose chains' length can significantly affect the untwisting process. The untwisting itself seems to promote the processes of cellulose disintegration. Basing on this theory, we have proposed that the low DP and short length oil flax cellulose should be easily grindable and convertible to the MCC and NC, which was confirmed experimentally.

The same tendency could be found in the process of cellulose nitration, where the kinetics of the nano-fibrils untwisting limits the overall rate of the reaction (Nikolsky et al., 2019). Given that the flax cellulose could be used as a raw for nitro-compounds production (Gismatulina et al., 2016; Sakovich et al., 2018), using the oil flax cellulose for the production of the varnishes seems to be very attractive. Indeed, the low DP cellulose nitration should take a shorter time at the lower temperature, simplifying and cheapening the production.

\section{Declarations}

\subsection{Funding}

The work was completed as a part of the state assignment (theme number AAAAA20-120013190076-0)

\subsection{Conflict of Interest}

Authors declare no conflict of interest. 
5.3 Authors' contributions

S. Nikolsky - experimental, cellulose processing and paper making;

D. Zlenko - experimental design, text writing;

A. Gatin - experimental, AFM;

M. Mikhaleva - experimental, AFM;

G. Politenkova - experimental, cellulose processing;

A. Lin - stripping machine construction;

I. Ermolin - stripping machine construction;

S. Stovbun - experimental design, text writing;

\section{References}

Abitbol T, Rivkin A, Cao Y, Nevo Y, Abraham E, Ben-Shalom T, Lapidot S, Shoseyov O (2016) Nanocellulose, a tiny fiber with huge applications. Current Opinion in Biotechnology 39:76-88

Anthony WS (2002) Separation of fiber from seed flax straw. Applied Engineering in Agriculture 18(2):227-233

Anthony WS (2005) Development of machines to separate fiber and shive from seed flax straw. Applied Engineering in Agriculture 21(6):1057-1063

Athukorala Y, Mazza G, Oomah BD (2009) Extraction, purification and characterization of wax from flax (Linum usitatissimum) straw. European Journal of Lipid Science and Technology 111(7):705-714

Azhar SW, Xu F, Zhang Y, Qiu Y, Qiu Y (2020) Fabrication and mechanical properties of flaxseed fiber bundle-reinforced polybutylene succinate composites. Journal of Industrial Textiles 50(1):98-113

Baley C (2002) Analysis of the flax fibres tensile behaviour and analysis of the tensile stiffness increase. Composites Part A: Applied Science and Manufacturing 33(7):939-948

Barneto AG, Vila C, Ariza J, Vidal T (2011) Thermogravimetric measurement of amorphous cellulose content in flax fibre and flax pulp. Cellulose 18(1):17-31

Bondeson D, Mathew A, Oksman K (2006) Optimization of the isolation of nanocrystals from microcrystalline cellulose by acid hydrolysis. Cellulose 13:171180

Buranov AU, Mazza G (2008) Lignin in straw of herbaceous crops. Industrial Crops and Products 28(3):237-259

Buranov AU, Mazza G (2010) Extraction and characterization of hemicelluloses from flax shives by different methods. Carbohydrate Polymers 79(1):17-25

Buranov AU, Ross KA, Mazza G (2010) Isolation and characterization of lignins extracted from flax shives using pressurized aqueous ethanol. Bioresource Technology 101(19):7446-7455

Determination of Cellulose H, in Flax Fiber LCUNIS (2009) Jing huang and chongwen yu. Textile Research Journal 89(23):4875-4883

Chursina L, Tikhosova H, Holovenko T, Shovkomud O, Kniaziev O, Yanyuk T (2019) Innovative technologies of oilseed flax straw mechanical processing and quality of obtained fibers. INMATEH - Agricultural Engineering 57(1):207-214

Dillman AC (1943) Paper from flax. US Department of Agriculture Yearbook 47:750-752 
El-Sakhawy M, Hassan ML (2007) Physical and mechanical properties of microcrystalline cellulose prepared from agricultural residues. Carbohydrate Polymers $67: 1-10$

Fernandes A, Thomas L, Altaner C, Callow P, Forsyth V, Apperley D, Kennedy C, Jarvis M (2011) Nanostructure of cellulose microfibrils in spruce wood. Proc Nat Acad Sci 108(47):E1195-E1203

Foulk J, Akin D, Dodd R, Ulven C (2011) Production of flax fibers for biocomposites. In: Kalia S, Kaith B, Kaur I (eds) Cellulose Fibers: Bio- and NanoPolymer Composites: Green Chemistry and Technology, Springer Berlin Heidelberg, Berlin, Heidelberg, pp 61-95

Gismatulina Y, Budaeva V, Sakovich G (2016) Cellulose nitrates from intermediate flax straw. Russian Chemical Bulletin 65(12):2920-2924

Hubbe MA, Ayoub A, Daystar JS, Venditti RA, Pawlak JJ (2013) Enhanced absorbent products incorporating cellulose and its derivatives: A review. BioResources 8(4):6556-6629

Khalil HA, Davoudpour Y, Islam MN, Mustapha A, Sudesh K, Dungani R, Jawaid M (2014) Production and modification of nanofibrillated cellulose using various mechanical processes: A review. Carbohydrate Polymers 99:649-665

Lazko J, Dupre B, Dheilly R, Queneudec M (2011) Biocomposites based on flax short fibres and linseed oil. Industrial Crops and Products 33(2):317-324

Liu J (2019) Nitrocellulose, Springer Nature Singapore, chap 10, pp 469-580

Lujan-Ornelas C, del CSternenfels UM, Güereca LP (2018) Life cycle assessment of mexican polymer and high-durability cotton paper banknotes. Science of the Total Environment 630:409-421

Lund K, Sjöström K, Brelid H (2012) Alkali extraction of kraft pulp fibers: Influence on fiber and fluff pulp properties. Journal of Engineered Fibers and Fabrics $7(2): 30-39$

Moon RJ, Martini A, Nairn J, Simonsen J, Youngblood J (2011) Cellulose nanomaterials review: Structure, properties and nanocomposites. Chemistry Society Review 40:3941-3994

Nikolsky SN, Zlenko DV, Melnikov VP, Stovbun SV (2019) The fibrils untwisting limits the rate of cellulose nitration process. Carbohydrate Polymers 204:232237

Nsor-Atindana J, Chen M, Goff HD, Zhong F, Sharif HR, Li Y (2017) Functionality and nutritional aspects of microcrystalline cellulose in food. Carbohydrate Polymers 172:159-174

Nuez L, Beaugrand J, Shah DU, Mayer-Laigle C, Bourmaud A, D'Arras P, Baley C (2020) The potential of flax shives as reinforcements for injection moulded polypropylene composites. Industrial Crops and Products 148:112324

Qing Y, Sabo R, Zhu J, Agarwal U, Cai Z, Wu Y (2013) A comparative study of cellulose nanofibrils disintegrated via multiple processing approaches. Carbohydrate Polymers 97:226-234

Richter G (1929) Process for the production of high-alpha cellulose fiber for the manufacture of cellulose derivatives. US Patent p 1741540 A

Sakovich G, Mikhailov Y, Budaeva V, Korchagina A, Gismatulina Y, Kozyrev N (2018) Cellulose nitrates from unconventional feedstocks. Doklady Chemistry 483(1):287-291

Schafer ER, Curran C (1938) Pulping and papermaking properties of seed flax straw. US Department of Agriculture, Forest Service, Forest Products Laoratory 


\section{Report:R1159}

Shaimerdenov ZN, Dalabayev AB, Temirova IZ, Aldiyeva AB, Sakenova BA, Zhunussova KZ, Iztayev A (2020) Fibre extraction from oilseed flax straw for various technical applications. EurAsian Journal of BioSciences 14(2):4287-4295

Stovbun SV, Skoblin AA, Zlenko DV (2018) Self assembly and gelation in solutions of chiral N-trifluoroacetylated $\alpha$-aminoalcohols. Chemical Physics 508:34-44

Stovbun SV, Mikhaleva MG, Skoblin AA, Usachev SV, Nikolskiy SN, Kharitonov VA, Kovaleva KI, Politenkova GG, Vedenkin AS, Zlenko DV (2020) Zhurkov's stress-driven fracture as a driving force of the microcrystalline cellulose formation. Polymers 12(12):2952

Tavisto M, Kuisma R, Pasila A, Hautala M (2003) Wetting and wicking of fibre plant straw fractions. Industrial Crops and Products 18(1):25-35

Terinte N, Ibbett R, Schuster KC (2011) Overview on native cellulose and microcrystalline cellulose I structure studied by X-ray diffraction (WAXD): Comparison between measurement techniques. Lenzinger Berichte 89:118-131

Trache D, Khimeche K, Mezroua A, Benziane M (2016) Physicochemical properties of microcrystalline nitrocellulose from Alfa grass fibres and its thermal stability. J Therm Anal Calorim 124:1485-1496

Tulloch A, Hoffman L (1977) Composition of wax from seed flax straw. Journal of the American Oil Chemists' Society 54:587-588

Ververis C, Georghiou K, Christodoulakis N, Santas P, Santas R (2004) Fiber dimensions, lignin and cellulose content of various plant materials and their suitability for paper production. Industrial Crops and Products 19(3):245-254

Wells SD (1949) Production of fiber from flax straw. US Patent pp No. 2641541

Whorlow R (1980) Rheological Techniques. Ellis Horwood, Chichester, UK

Yousef S, Eimontas J, Striugas N, Trofimov E, Hamdy M, Abdelnaby MA (2020) Conversion of end-of-life cotton banknotes into liquid fuel using mini- pyrolysis plant. Journal of Cleaner Production 267:121612

Zhao Z, Shklyaev O, Nili A, Mohamed M, Kubicki J, Crespi V, Zhong L (2013) Cellulose microfibril twist, mechanics, and implication for cellulose biosynthesis. J Phys Chem A 117:2580-2589

Zlenko DV, Nikolsky SN, Vedenkin AS, Politenkova GG, Skoblin AA, Melnikov VP, Mikhaleva MG, Stovbun SV (2019a) Twisting of fibers balancing the gel-sol transition in cellulose aqueous suspensions. Polymers 11:873

Zlenko DV, Zanin AM, Skoblin AA, Stovbun SV (2019b) Dispersed phase particles in the solutions of chiral trifluoroacetylated $\alpha$-aminoalcohols. Chemical Physics 518:74-80

Zykova A, Pantyukhov P, Popov A (2011) Ethylene-octene copolymer-wood flour/oil flax straw biocomposites: Effect of filler type and content on mechanical properties. Polymer Engineering and Science 57(7):756-763 